Review began 09/17/2021 Review ended 10/03/2021 Published 10/07/2021

(c) Copyright 202

Portocarrero Bonifaz et al. This is an open access article distributed under the terms of the Creative Commons Attribution License CC-BY 4.0., which permits unrestricted use, distribution, and reproduction in any medium, provided the original author and source are credited.

\section{Diagnostic Reference Levels for Common X-ray Procedures in Peru}

\author{
Andres Portocarrero Bonifaz ${ }^{1,2}$, Caterina S. Camarena Rodriguez ${ }^{3}$, Ricardo Palma Esparza ${ }^{3}$ \\ 1. Radiation Oncology, University of Louisville, Louisville, USA 2. Physics, Pontificia Universidad Catolica del Peru, \\ Lima, PER 3. Control de Calidad en Radiodiagnostico, OC Dose S.A.C, Lima, PER
}

Corresponding author: Andres Portocarrero Bonifaz, aportocarrerob@pucp.edu.pe

\begin{abstract}
Diagnostic reference levels (DRLs) for X-ray procedures have been established in many countries since 1996. In Peru, data from the literature are used as guidelines as DRLs research is limited. The objective of this study is to analyze the parameters and variables which are used in radiological techniques such as kV, mAs, and type of machine (conventional or digital); study the geographical distribution of radiological X-ray machines, and establish DRLs in Peru. Two radiological procedures were considered, general X-rays (fixed and mobile) and intraoral X-rays (fixed, mobile, and portable). An Unfors RaySafe Xi detector (Unfors RaySafe AB, Billdal, Sweden) was used; air kerma was measured at a source to image distance that varied depending on the procedure, and the entrance skin dose was subsequently calculated using the Arcal XLIX formalism. The data were collected over a period of three years (2015-2017). Only results from the last evaluation during this period were taken into consideration for each X-ray machine. DRLs were calculated at $0.21 \mathrm{mSv}$, and $0.25 \mathrm{mSv}$ for posterior-anterior chest examinations in conventional and digital machines, respectively; $4.39 \mathrm{mSv}$ and $6.01 \mathrm{mSv}$ for conventional and digital antero-posterior lumbar spine examinations, respectively; and at $4.21 \mathrm{mSv}$ for the dental intraoral procedure. The largest amount of X-ray machines is concentrated in the city of Lima. These results reflect the standard of practice in Peru.
\end{abstract}

Categories: Medical Physics, Radiology

Keywords: peru, quality control, dose, intraoral x-rays, general x-rays, drl, diagnostic reference levels

\section{Introduction}

The absorbed dose, in matters of ionizing radiation, is the energy deposited per kilogram and it is represented by the Gray (Gy) in the international system of units. When the absorbed dose is multiplied by a weighting factor that depends on the type of radiation, it is known as the equivalent dose and its unit is the Sievert (Sv). For the case of X-rays, the weighting factor is one [1,2].

Research has shown that the difference between the minimum dose in one diagnostic center and the maximum dose in another can be up to 50 times as much [3]. Taking into account the principle of optimization, and having found these inconsistencies, the term "Diagnostic Reference Value" was proposed in 1990 [4].

The diagnostic reference level (DRL) value was first introduced in publication 73 of the International Commission on Radiological Protection (ICRP) [5]. The main objective was to establish a standard for the various techniques in radiological procedures [6]. In Peru, law 28028 [7], with its technical standard IR 003 2013, stipulates that the representative doses for patients must be determined for different radiographic procedures and that X-ray examinations must comply with the principles of justification, and optimization [8]. However, research in Peru for the establishment of DRLs is limited [9].

A DRL value can be of three types: national, regional, or local. National reference levels are established at the $75 \%$ percentile of the median DRL values of health facilities in a country. However, ICRP mentions in its report 135 that an even greater optimization can be made if the $50 \%$ percentile is used. If an institution falls below this benchmark, it is recommended to focus on improving its diagnostic image quality, rather than reducing radiation levels [10].

In Peru, the organization that is dedicated to the regulation and control of ionizing radiation sources is the "Oficina Técnica de Autoridad Nacional" (OTAN). X-ray machines quality control services guarantee that the equipment is working correctly; it must be done annually for general radiology machines and every three years for intraoral dental X-ray machines [8].

Currently, one of the most widely used medical imaging quality control protocols in Peru is Arcal XLIX. The accepted limit for entrance skin dose for intraoral dental machines is $7 \mathrm{mGy}$ [11]; while for general X-rays is $0.4 \mathrm{mGy}$ for posteroanterior chest (PA), and $10 \mathrm{mGy}$ for anteroposterior lumbar spine (AP) [12].

The objective of this study was to obtain Peruvian DRLs for intraoral and general X-rays (chest PA and lumbar Spine AP), study the parameters and variables which are used in radiological techniques such as $\mathrm{kV}$, 
mAs, and type of machines, and analyze the geographical distribution of X-ray machines in the country. This article was previously presented as a Poster at the 2019 International Conference on Medical Physics Scientific Meeting on September 8, 2019.

\section{Materials And Methods}

A descriptive cross-sectional study was carried out. To obtain the study database, the quality control reports prepared by QC Dose SAC's Department of Quality Control for Medical Imaging performed to X-ray machines of various public and private health centers were used; the data collection period lasted three years (2015-2017). To maintain the anonymity of each health facility, a code was assigned to each report. The information from 397 general X-ray machines and 254 intraoral dental machines was used.

In order to calculate the DRLs for common general radiology techniques (PA Chest and AP Lumbar Spine) and dental - intraoral examinations [13,14], the entrance skin dose was calculated with the data obtained from an Unfors RaySafe Xi detector with the method recommended by the Arcal XLIX protocol (Equation 1) [12]. This instrument has an air kerma measurement uncertainty of 5\%; it was calibrated annually in the United States and was used throughout the study period [15].

For the analysis of the radiation technique parameters, the X-ray technicians were asked to obtain a radiographic image using the parameters of a standard adult patient (18 years old or older). The health facilities where pediatric evaluations are carried out were not taken into account for this study, nor were those that exceeded the permissible limits according to the Arcal XLIX protocol.

The entrance skin dose was calculated using Equation 1:

$D_{s}=K_{\mathrm{air}} \times\left(\frac{\mathrm{SID}}{\mathrm{SSD}}\right)^{2} \times \mathrm{BSF}$

Equation 1. $D_{s}$ is the entrance skin dose. $K_{\text {air }}$ is the air kerma value obtained from the Unfors RaySafe Xi detector. $\left(\frac{\mathrm{SD}}{\mathrm{SSD}}\right)^{2}$ is the inverse correction factor, SID is the source-image distance and SSD is the sourcesurface distance. Finally, BSF is the backscattering factor. The values referenced in the Arcal XLIX for the BSF (PA Chest and AP Lumbar Spine: 1.4; Dental - Intraoral: 1.2), and for the standard thickness for chest and lumbar spine $(23 \mathrm{~cm})$, were taken into consideration.

As suggested by international literature, the national DRLs were calculated at the $75 \%$ percentile (P75) of the median of the diagnostic reference levels of health facilities distributed nationwide [10,16-18]. P50 was also calculated in order to have a reference for optimization purposes.

Statistical analysis was performed using IBM SPSS Statistics Version 24.0 (IBM Corp. Armonk, NY, USA) [19]. Various descriptive statistics and measures of central tendency were found. In addition to the dose, the parameters of the radiological techniques (kV, mAs) were studied for each different examination.

X-ray machines were also grouped into two areas: Lima (capital of Peru) or all the other departments combined together, and type of machines: digital or conventional.

\section{Results}

The obtained results are presented below.

Table 1 establishes the DRLs (P75) for PA Chest (Conventional and Digital), AP lumbar spine (Conventional and Digital), and intraoral radiographs. Additionally, the number of health facilities evaluated, the standard deviation, and the value of P50 are presented.

\begin{tabular}{|c|c|c|c|c|c|}
\hline & Chest (C) & Spine (C) & Chest (D) & Spine (D) & Intraoral \\
\hline Health Centers Number & 221 & 167 & 65 & 62 & 182 \\
\hline Std (mSv) & 0.09 & 1.98 & 0.11 & 2.6 & 1.51 \\
\hline P50 (mSv) & 0.14 & 2.91 & 0.15 & 4.29 & 2.87 \\
\hline P75 (mSv) & 0.21 & 4.39 & 0.25 & 6.01 & 4.21 \\
\hline
\end{tabular}

TABLE 1: P50 and P75 of the median doses in health facilities, for the different X-ray techniques.

Figure $1 \mathrm{~A}$ shows the box-plot graphs for Conventional spine, Digital spine, and Intraoral X-ray examinations 


\section{Cureus}

in order to better visualize the spread of the experimental data. Likewise, Figure $1 B$ shows the box-plot graph for the Conventional chest and Digital chest.
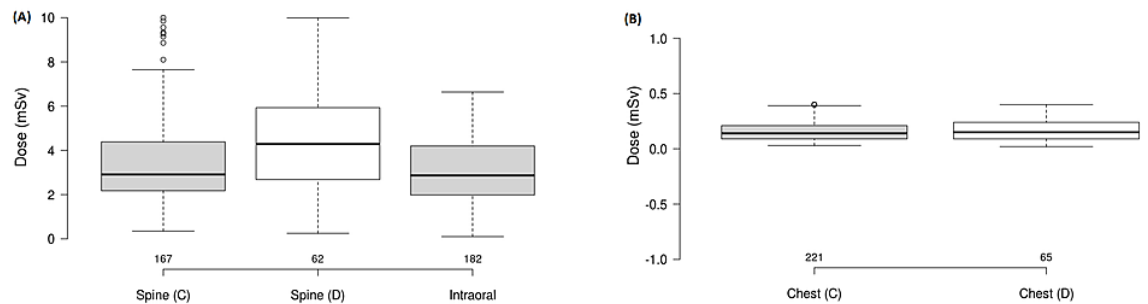

FIGURE 1: Box-plot graphs for the health centers' median dose values

Figures $2 A-2 C$ show the frequency distribution of the median dose values for the health centers of the X-ray examinations considered for this study (PA Chest, AP lumbar spine, and intraoral). The value of the third percentile (P75) was marked in each histogram with a red dashed line according to the modalities shown in Table 1 .
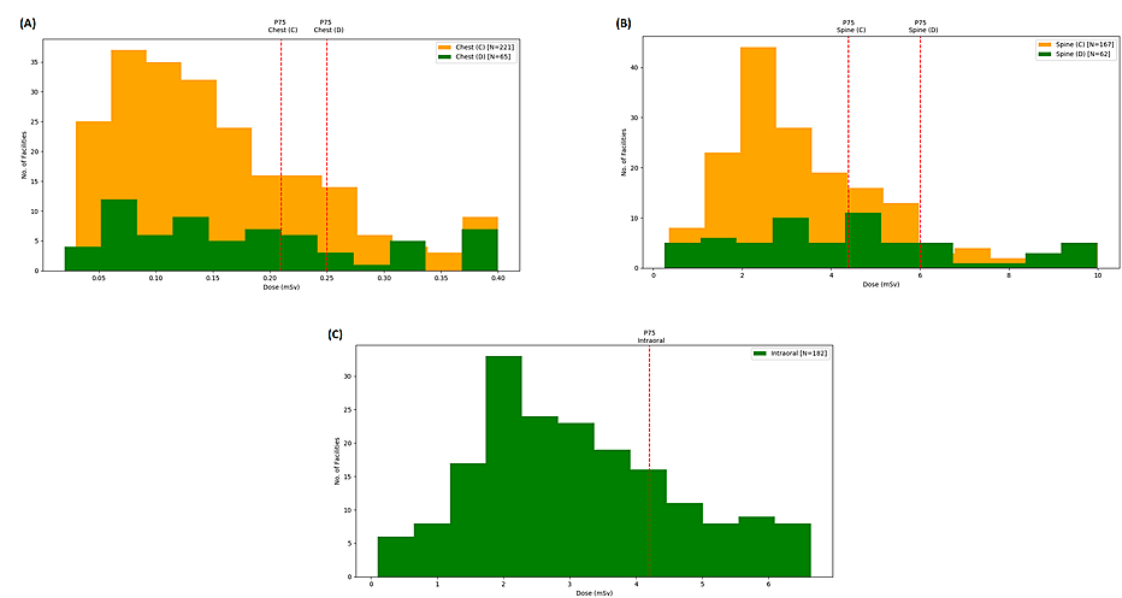

FIGURE 2: Frequency distribution of the health centers' median doses

Table 2 contains the descriptive statistics for the parameters $(\mathrm{kV}$ and $\mathrm{mAs})$ that are used in general X-ray for conventional and digital machines. Two types of examinations were studied in each of the cases, PA chest and AP lumbar spine. 


\section{Cureus}

\begin{tabular}{|c|c|c|c|c|}
\hline & Chest (C) & Spine (C) & Chest (D) & Spine (D) \\
\hline Min. (kV) & 50 & 50 & 60 & 68 \\
\hline Max. (kV) & 129 & 150 & 125 & 110 \\
\hline Mode (kV) & 70 & 75 & 70 & 75 \\
\hline Std (kV) & 16.4 & 9.28 & 17.86 & 8.01 \\
\hline Min. (mAs) & 0.4 & 3.2 & 0.25 & 0.4 \\
\hline Max. (mAs) & 40 & 123.75 & 16 & 80 \\
\hline Mode (mAs) & 4 & 20 & 3.2 & 25 \\
\hline Std (mAs) & 4.25 & 19.36 & 3.02 & 16.77 \\
\hline
\end{tabular}

TABLE 2: Analysis of general X-ray techniques for conventional and digital machines

Figure 3 shows the distribution of X-ray machines. It can be seen that the majority of digital machines is found in the capital (79.8\%), as well as a greater number of intraoral (67.8\%) and conventional (54.8\%) machines, in comparison with all the other departments combined.

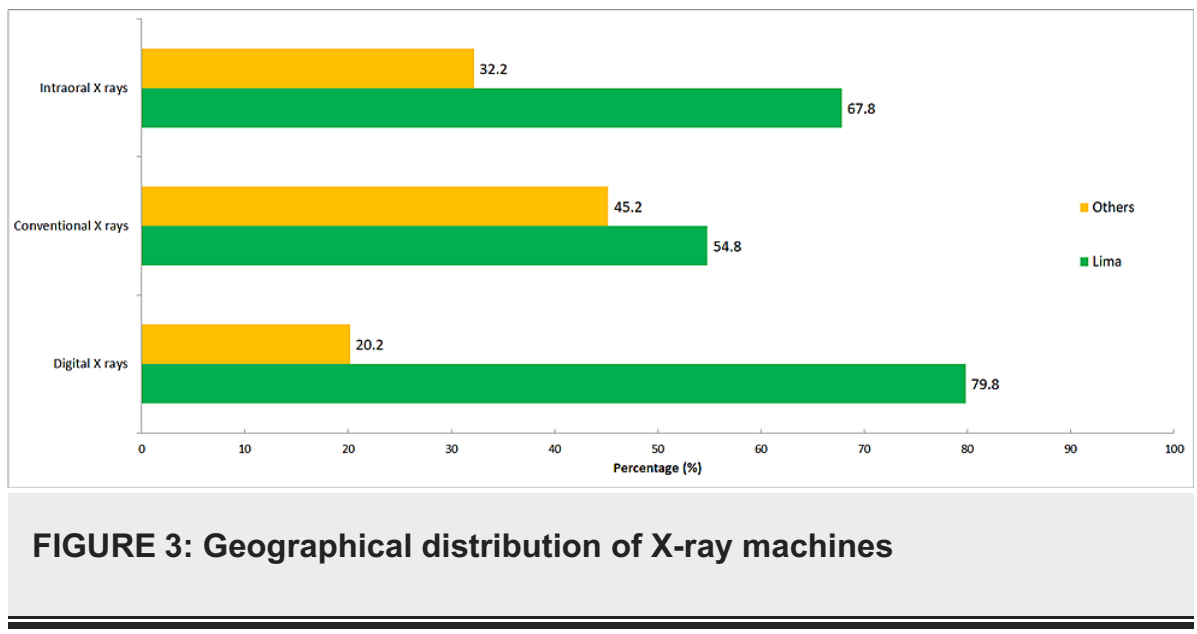

\section{Discussion}

The DRLs for intraoral dental radiographs differ but stay within the same range from the results obtained by Kim et al. [17] in Korea, where the 75th percentile for an adult molar examination was $3.07 \mathrm{mSv}$. Likewise, the results obtained for general radiographic examinations vary from those obtained by Kiljunen et al. [18] in Slovenia, Sonawane et al. [20] in India, and Uniyal et al. [21] in India. The first authors obtained a value of the 75 th percentile of lumbar spine AP of $7.98 \mathrm{mSv}$ and of $0.35 \mathrm{mSv}$ for chest PA. In the case of Sonawane et al. [20], they obtained values of lumbar spine AP of $8.39 \mathrm{mSv}$ and of $0.68 \mathrm{mSv}$ for chest PA. Finally, Uniyal et al. [21] obtained values of $8.55 \mathrm{mSv}$ for lumbar spine AP and $0.43 \mathrm{mSv}$ for chest PA. Moreover, DRLs also differ but were found on the same range when compared with Lithuania, whose reference diagnostic values are $9 \mathrm{mSv}$ for lumbar spine AP and $0.6 \mathrm{mSv}$ for chest PA [22], Switzerland with values of $8.7 \mathrm{mSv}$ for lumbar spine AP and $0.2 \mathrm{mSv}$ for chest PA [23], and the United Kingdom, whose DRLs are $5 \mathrm{mSv}$ for lumbar spine AP and $0.15 \mathrm{mSv}$ for chest PA [24]. It can be seen that the DRLs obtained in each country vary minimally. This is because the DRLs reflect local standards, and the optimization process must be approached from a nationallevel perspective $[25,26]$.

Due to the differences in dose between conventional and digital general radiography X-ray examinations, which are characterized by their flexibility regarding dose and image quality [27], it is recommended to study both modalities separately and establish DRL for each modality. The DRLs for conventional and digital machines vary approximately in $2 \mathrm{mSv}$ for lumbar spine AP (Table 1). It is important to emphasize that the ionizing radiation limits established in the protocols should not be exceeded, since when this occurs, the risk of generating a stochastic effect in the patient increases, and quality standards are not met.

On the other hand, when studying the parameters with which the various radiographic techniques are taken, discrepancies were found between health facilities (Table 2). It should be noted that the parameters depend on the X-ray machines and their condition; however, the modes of the various parameters give indicative 
Likewise, it is worth mentioning that all departments combined have a greater national territory, as well as a greater amount of population, compared to the capital (Lima). However, most of the X-ray machines are found in the latter (Figure 3). Furthermore, $80 \%$ of the machines for digital radiography in Peru are in Lima. This may be due to the centralization that exists in Peru [28], and/or the lack of request for quality services for X-ray machines located outside the capital.

The greatest limitation of the present study is the size of the sample and the number of measurements taken for each machine; although the number of evaluated machines is high, it is recommended to increase the sample to obtain more reliable results, and to have more measurements in each machine; according to ICRP 135 [10], it is recommended to take measurements in at least 20 patients for general X-ray examinations. Finally, bias is introduced by the X-ray technicians when asked to irradiate based on a "Standard Adult Patient," as they make an estimate of the technique based on experience.

\section{Conclusions}

In conclusion, it is observed that DRLs for general X-rays and intraoral dental X-rays have been derived and can be used as references for optimization. With regard to radiological techniques, it was found that there are discrepancies between health establishments and that these parameters can impact the dose to the patient; for these reasons, continuous training is recommended in order to select the most appropriate technique. Finally, it is appreciated that there is a great technological concentration in the capital with respect to all the other departments, even more so when it comes to digital radiology machines.

\section{Additional Information \\ Disclosures}

Human subjects: All authors have confirmed that this study did not involve human participants or tissue. Animal subjects: All authors have confirmed that this study did not involve animal subjects or tissue. Conflicts of interest: In compliance with the ICMJE uniform disclosure form, all authors declare the following: Payment/services info: All authors have declared that no financial support was received from any organization for the submitted work. Financial relationships: All authors have declared that they have no financial relationships at present or within the previous three years with any organizations that might have an interest in the submitted work. Other relationships: All authors have declared that there are no other relationships or activities that could appear to have influenced the submitted work.

\section{References}

1. Okano T, Sur J: Radiation dose and protection in dentistry. Jpn Dent Sci Rev. 2010, 46:112-21. 10.1016/j.jdsr.2009.11.004

2. Khan FM, Gibbons JP: Khan's the Physics of Radiation Therapy. Lippincott Williams \& Wilkins, Philadelphia; 2014.

3. Olarinoye I, Sharifat I: A protocol for setting dose reference level for medical radiography in Nigeria: a review. Bayero J Pure Appl Sci. 2010, 3:138-141. 10.4314/bajopas.v3i1.58748

4. Muhammad NA, Abdul Karim MK, Abu Hassan H, Ahmad Kamarudin M, Ding Wong JH, Ng KH: Diagnostic reference level of radiation dose and image quality among paediatric CT examinations in a tertiary hospital in Malaysia. Diagnostics (Basel). 2020, 10:10.3390/diagnostics10080591

5. International Commission on Radiological Protection: ICRP publication 73: radiological protection and safety in medicine. Ann ICRP. 1996, 26:1-31. 10.1016/s0146-6453(00)89195-2

6. Hoseini Motlagh Z, Shabestani Monfared A, Deevband MR, Abedi-Firouzjah R, Ghaemian N, Abdi R, Ebrahimnejad Gorji K: Determination of diagnostic reference level in routine examinations of digital radiography in Mazandaran province. Radiat Prot Dosimetry. 2020, 190:31-7. 10.1093/rpd/ncaa074

7. Ley 28028: Ley de regulación del uso de fuentes de radiación ionizante . (2003). Accessed: September 11, 2021: https://www.ipen.gob.pe/transparencia/regulacion/normatividad/ley_28028.htm.

8. IR.003.2013: Requisitos para protección radiológica en diagnóstico médico con rayos X . (2013). Accessed: September 11, 2021: http://limacap.org/normatividad-2019/normas-salud/IPEN_Norma_pr_diag_medic_RX2013.pdf.

9. Blanco S, Mora P, Almonte N, et al.: Determination of diagnostic reference levels in general radiography in Latin America. Radiat Prot Dosimetry. 2013, 156:303-9. 10.1093/rpd/nct069

10. Vañó E, Miller DL, Martin CJ, et al.: ICRP Publication 135: diagnostic reference levels in medical imaging . Ann ICRP. 2017, 46:1-144. 10.1177/0146645317717209

11. González L, Vañó E, Fernández R: Reference doses in dental radiodiagnostic facilities . Br J Radiol. 2001, 74:153-6. 10.1259/bjr.74.878.740153

12. Protocolos de control de calidad en radiodiagnóstico: ARCAL XLIX . (2001). Accessed: September 11, 2021: http://www.proteccionradiologica.cl/wp-content/uploads/2016/08/PROTOCOLO-ARCAL-XLIX.pdf.

13. Célier D, Roch P, Etard C, Ducou Le Pointe H, Brisse HJ: Multicentre survey on patient dose in paediatric imaging and proposal for updated diagnostic reference levels for France. Part 2: plain radiography and diagnostic fluoroscopy. Eur Radiol. 2020, 30:1182-90. 10.1007/s00330-019-06406-2

14. Trindade H, Coutinho G: Dental intraoral exposures in Portugal: from 1990 to 2018. Radiat Prot Dosimetry. 2019, 185:452-5. 10.1093/rpd/ncz033

15. Raysafe Xi Classic specifications. (2015). Accessed: September 11, 2021:

https://www.flukebiomedical.com/sites/default/files/resources/5200043_2.1_RaySafe_Xi_Classic_Specifications_EN_web.pd 
16. Johnston DA, Brennan PC: Reference dose levels for patients undergoing common diagnostic X-ray examinations in Irish hospitals. Br J Radiol. 2000, 73:396-402. 10.1259/bjr.73.868.10844865

17. Kim EK, Han WJ, Choi JW, Jung YH, Yoon SJ, Lee JS: Diagnostic reference levels in intraoral dental radiography in Korea. Imaging Sci Dent. 2012, 42:237-42. 10.5624/isd.2012.42.4.237

18. Kiljunen T, Järvinen H, Savolainen S: Diagnostic reference levels for thorax X-ray examinations of paediatric patients. Br J Radiol. 2007, 80:452-9. 10.1259/bjr/60918774

19. IBM SPSS. (2021). Accessed: October 2, 2021: https://www.ibm.com/products/spss-statistics.

20. Sonawane AU, Shirva VK, Pradhan AS: Estimation of skin entrance doses (SEDs) for common medical X-ray diagnostic examinations in India and proposed diagnostic reference levels (DRLs). Radiat Prot Dosimetry. 2010, 138:129-36. 10.1093/rpd/ncp235

21. Uniyal SC, Chaturvedi V, Sharma SD, Raghuvanshi S: Estimation of entrance surface air kerma due to diagnostic X-ray examinations of adult patients in Uttarakhand, India and establishment of local diagnostic reference levels. Australas Phys Eng Sci Med. 2017, 40:687-94. 10.1007/s13246-017-0577-8

22. Ziliukas J, Morkunas G: Results of a patient dose survey on diagnostic radiology in Lithuania . Radiat Prot Dosimetry. 2005, 114:172-5. 10.1093/rpd/nch529

23. Aroua A, Besançon A, Buchillier-Decka I, Trueb P, Valley JF, Verdun FR, Zeller W: Adult reference levels in diagnostic and interventional radiology for temporary use in Switzerland. Radiat Prot Dosimetry. 2004, 111:289-95. 10.1093/rpd/nch343

24. Doses to patients from radiographic and fluoroscopic X-ray imaging procedures in the UK . (2012). Accessed: October 7, 2021:

https://assets.publishing.service.gov.uk/government/uploads/system/uploads/attachment_data/file/431134/HPARPD-029.pdf.

25. Guidance on diagnostic reference levels (DRLs) for medical exposures . (1999). Accessed: October 7, 2021: https://ec.europa.eu/energy/sites/ener/files/documents/109_en.pdf.

26. Bas Mor H, Altinsoy N, Söyler I: Estimation of adult patient doses for chest x-ray examinations and comparison with diagnostic reference levels (DRLs). Radiat Prot Dosimetry. 2018, 182:377-85. 10.1093/rpd/ncy076

27. Uffmann M, Schaefer-Prokop C: Digital radiography: the balance between image quality and required radiation dose. Eur J Radiol. 2009, 72:202-8. 10.1016/j.ejrad.2009.05.060

28. La reforma del estado en Perú . (2006). Accessed: September 11, 2021: http://idbdocs.iadb.org/wsdocs/getdocument.aspx?docnum=1004083. 